\title{
A Novel Sensitive Doxorubicin Hydrochloride Electrochemical Sensor Based on a Nickel Hexacyanoferrate/Ni-Al-LDH Modified Gold Electrode
}

\author{
Lei Lü \\ Institute of Chemical Technology, Shanxi Normal University, Linfen 041004, P. R. China
}

\begin{abstract}
A highly sensitive and selective electrochemical sensor has been fabricated by the electrodepositing of nickel hexacyanoferrate (NiHCF) on a Ni-Al layered double hydroxides (Ni-Al-LDH) modified Au electrode for the quantification of doxorubicin hydrochloride (DOX). The characterization of synthesized nanomaterials has been conducted by scanning electron microscopy, energy dispersive X-ray spectroscopy and electrochemical methods. The synergistic effect of NiHCF and Ni-Al-LDH not only excellently improves the performance of DOX electro-reduction, but also promotes electron transfer between DOX and the NiHCF/Ni-Al-LDH/Au sensor. The differential pulse voltammetric response of the NiHCF/Ni-Al-LDH/Au sensor shows a linear relationship with the concentration of DOX in the range of $1.0 \times 10^{-8}$ $-6.2 \times 10^{-6} \mathrm{~mol} \mathrm{~L}^{-1}$, a limit of detection of $1.9 \times 10^{-9} \mathrm{~mol} \mathrm{~L}^{-1}(\mathrm{~S} / \mathrm{N}=3)$ and a sensibility of $14.71 \mathrm{~A} \mathrm{~mol} \mathrm{~L}^{-1} \mathrm{~cm}^{-2}$. The developed sensor exhibits good sensitivity, reproducibility, anti-interference and a long-term stability property. Furthermore, the NiHCF/Ni-Al-LDH/Au sensor has been successfully applied to determine DOX in biological samples and human blood serum samples.
\end{abstract}

Keywords Electrochemical sensor, doxorubicin hydrochloride, nickel hexacyanoferrate, double hydroxides

(Received July 19, 2019; Accepted August 20, 2019; Advance Publication Released Online by J-STAGE August 30, 2019)

\section{Introduction}

Doxorubicin hydrochloride (DOX, Scheme 1) as an anthracycline drug is extensively used in the treatment of many different types of cancers, such as leukemia, neuroblastoma, sarcomas and carcinoma. However, excess DOX can cause serious side effects, e.g., cardiac and liver toxicity as well as drug resistance, ${ }^{1,2}$ limiting its clinical application to a certain degree. Therefore, it is of great significance to explore a reliable and sensitive detection method for trace amounts of DOX in biological samples. Until now, several analytical techniques including spectrometry, ${ }^{3,4}$ mass spectrometry, ${ }^{5}$ high-performance liquid chromatography, ${ }^{6}$ liquid chromatography-mass spectrometry, ${ }^{7}$ and electroanalytical techniques ${ }^{8-12}$ have been developed to detect DOX in different biological samples. Among these techniques, due to the rapid, simple, low cost and high sensitivity, electrochemical analysis methods based on modified electrodes have been attracted great attention and proven to be convenient for determining DOX because DOX molecule contains electroactive quinone and hydroquinone groups. At present, modified electrodes such as polymerization of magnetic graphene oxide grafted with chlorosulfonic acid modified electrode ( $\left.\mathrm{PS} / \mathrm{Fe}_{3} \mathrm{O}_{4}-\mathrm{GO}-\mathrm{SO}_{3} \mathrm{H} / \mathrm{GCE}\right){ }_{,}^{8}$ poly-arginine modified glassy carbon electrode (PARG/GCE), ${ }^{9}$ oxidized multiwalled carbon nanotube modified glassy carbon electrode (OMWCNT/ $\mathrm{GCE})^{10}$ as well as molecular imprinted polymer modified $\mathrm{Au}$ electrode (MIP/Au electrode) $)^{11}$ have been used for determining DOX. However, the preparations of these modified electrodes

E-mail: 1vlei@sxnu.edu.cn are complicated and time-consuming. Therefore, it is necessary to fabricate a more simple, stable, sensitive and efficient electrochemical sensor for detecting the target. ${ }^{13-15}$

Layered double hydroxides (LDH), named anionic clays or hydrotalcite-like compounds, have received much attention recently because of their potential applications in catalysis and adsorption, such as high adsorption capacity, high chemical stability, catalytic activity, etc. The LDH composition can be denoted as $\left[\mathrm{M}^{2+}{ }_{1-\mathrm{x}} \mathrm{M}^{3+}{ }_{\mathrm{x}}(\mathrm{OH})_{2}\right]\left[\mathrm{A}^{\mathrm{n}-}\right]_{\mathrm{x} / \mathrm{n}} z \cdot \mathrm{H}_{2} \mathrm{O}$ formula, of which $\mathrm{M}^{2+}$ and $\mathrm{M}^{3+}$ refer to the common divalent and trivalent metal ions, $\mathrm{A}^{\mathrm{n}-}$ is any type of anion. ${ }^{16-18}$ LDHs as weakly conductive solids restrict its electrochemical performance. ${ }^{19}$ However, because of the higher anion-exchange capacity and larger specific surface area, it can be served as support material for immobilizing some molecules with negative charge and electroactivity. ${ }^{20,21}$ Electrochemical sensors based on electroactive molecules immobilized onto a LDH surface, for example, $\mathrm{Fe}(\mathrm{III}) / \mathrm{Fe}(\mathrm{II})$ couple in nickel hexacyanoferrate<smiles>COc1cccc2c1C(=O)c1c(O)c3c(c(O)c1C2=O)C[C@@](O)(C(=O)CO)C[C@H]3O[C@@H]1C[C@H](N)[C@H](O)[C@H](C)O1</smiles>

Scheme 1 Molecular structure of doxorubicin hydrochloride. 
(A)

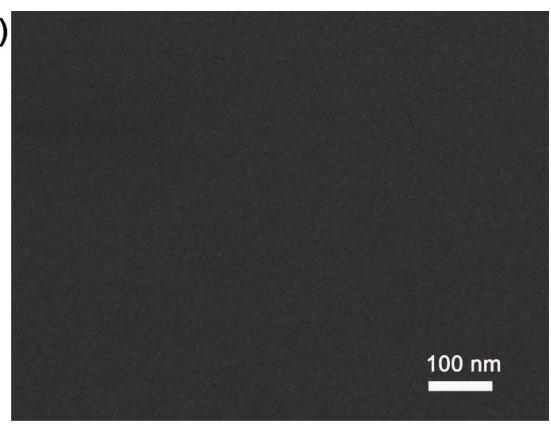

(C)

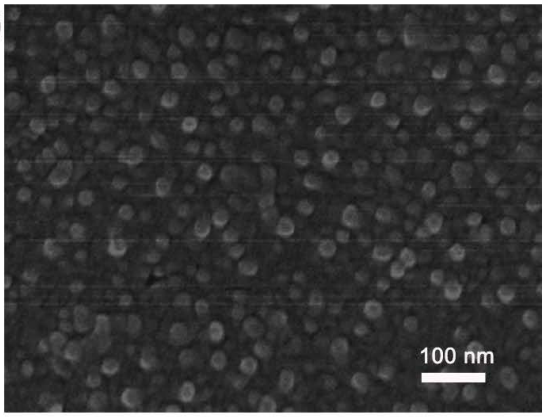

(B)

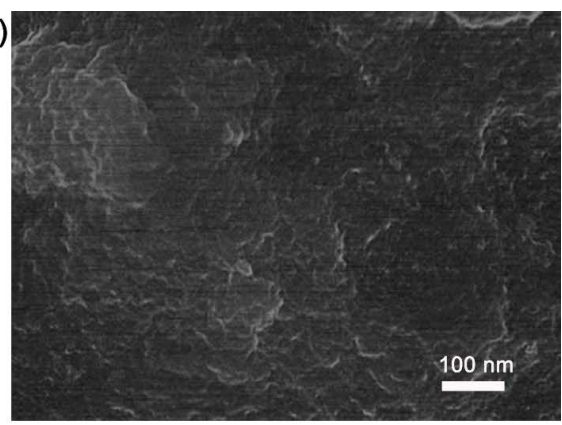

(D)

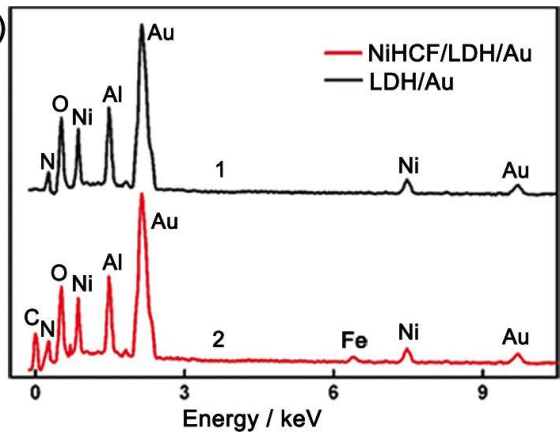

Fig. 1 SEM images of a bare Au electrode (A), Ni-Al-LDH/Au electrode (B) and NiHCF/Ni-Al$\mathrm{LDH} / \mathrm{Au}$ electrode $(\mathrm{C})$, as well as the EDX spectra of Ni-Al-LDH/Au and NiHCF/Ni-Al-LDH/Au electrodes (D).

$\left(\left[\mathrm{Fe}(\mathrm{CN})_{6}\right] \mathrm{Ni}_{2}\right.$, denoted as $\left.\mathrm{NiHCF}\right)$, have greatly enhanced the catalytic performances. ${ }^{22,23} \mathrm{NiHCF}$, an important inorganic polymeric compound, has received great attention for its advantages, i.e., open zeolite-like structure, interesting magnetic, and so on. Because of the reversibility of its redox reactions, ${ }^{24,25}$ $\mathrm{NiHCF}$ as an electron-transfer mediator, has been extensively applied to modify electrode surfaces in analytical applications. ${ }^{26-28}$

In this work, a NiHCF/Ni-Al-LDH/Au sensor was fabricated by an electrodeposition technique, which exhibits considerable electrocatalytic activity for the detection of DOX using a differential pulse voltammetry (DPV) method. This proposed method for determining DOX exhibits a wide linear range and low detection limit. Moreover, the fabricated sensor was used to detect DOX in human blood serum samples, which provides a novel platform for analyzing DOX in biological samples.

\section{Experimental}

\section{Reagents and chemicals}

Doxorubicin hydrochloride (DOX) was obtained from Hefei Bomei Biotechnology (Hefei, China). $\mathrm{Al}\left(\mathrm{NO}_{3}\right)_{3} \cdot 9 \mathrm{H}_{2} \mathrm{O}$, $\mathrm{K}_{4}\left[\mathrm{Fe}(\mathrm{CN})_{6}\right], \mathrm{NaNO}_{3}, \mathrm{Ni}\left(\mathrm{NO}_{3}\right)_{2} \cdot 6 \mathrm{H}_{2} \mathrm{O}, \mathrm{K}_{3}\left[\mathrm{Fe}(\mathrm{CN})_{6}\right]$ and $\mathrm{KNO}_{3}$ were purchased from Tianjin Guangfu Fine Chemical Research Institute. All chemical reagents were of analytical grade, and ultrapure water was used throughout all experiments.

\section{Apparatus}

The electrochemical experiments were employed with a CHI660E electrochemical analyzer ( $\mathrm{CH}$ Instruments Inc., Shanghai, China) with a common three-electrode system under ambient temperature. The bare/modified $\mathrm{Au}$ electrode $(\phi=$ $2 \mathrm{~mm}$ ), $\mathrm{Ag} / \mathrm{AgCl}$ (sat. $\mathrm{KCl}$ ) and platinum wire were employed as the working electrode, reference electrode and auxiliary electrode, respectively. During the measurement, all solutions were purged with nitrogen to eliminate oxygen reduction waves. The $\mathrm{pH}$ measurements were conducted on a PHS-3C exact digital pH meter (Leici Instrumental Factory, Shanghai, China). Scanning electron microscopy (SEM) images were collected on a JSM-7500F (JEOL, Japan), equipped with energy-dispersive $\mathrm{X}$-ray spectrometry (EDX).

\section{Preparation of blood plasma samples}

Blood plasma samples were obtained from Shuozhou Modern Hospital. For the preparation of serum samples, $1.2 \mathrm{~mL}$ of acetonitrile was added to $2 \mathrm{~mL}$ of healthy plasma sample. The mixture was centrifuged for about $15 \mathrm{~min}$ at $10000 \mathrm{rpm}$ to eliminate the serum proteins. Then, $100 \mu \mathrm{L}$ of the supernatant was diluted to $10 \mathrm{~mL}$ with a phosphate buffer solution (PBS, $\mathrm{pH}$ 7.4). The recovery percent was conducted by the DPV technique and standard addition method.

\section{Fabrication of modified electrodes}

Before using, a bare Au electrode was burnished with 0.3 and $1.0 \mu \mathrm{m}$ alumina powder, respectively, and was then rinsed successively with ultrapure water, ethanol, $\mathrm{HNO}_{3}(\mathrm{v} / \mathrm{v}=1: 1)$ and ultrapure water. Then, the bare Au electrode was activated in a $0.5 \mathrm{~mol} \mathrm{~L}^{-1} \mathrm{H}_{2} \mathrm{SO}_{4}$ solution by cycling in the potential range of $0-1.6 \mathrm{~V}$ for 20 circles, and dried at room temperature. Additionally, a Ni-Al-LDH modified Au electrode (Ni-Al-LDH/ $\mathrm{Au}$ ) and a NiHCF/Ni-Al-LDH/Au electrode were fabricated according to the literature, ${ }^{29}$ of which the general formula of $\mathrm{Ni}-\mathrm{Al}-\mathrm{LDH}$ is $\left[\mathrm{Ni}^{2+}{ }_{1-\mathrm{x}} \mathrm{Al}^{3+}{ }_{\mathrm{x}}(\mathrm{OH})_{2}\right]\left[\mathrm{NO}_{3}{ }^{\mathrm{n}-}\right]_{\mathrm{x} / \mathrm{n}} \mathrm{z} \cdot \mathrm{H}_{2} \mathrm{O}$.

\section{Electrochemical measurements}

Aften $0.2 \mathrm{~mol} \mathrm{~L}^{-1} \mathrm{PBS}$ was selected as the electrolyte solution for detecting DOX in all experiments, cyclic voltammograms (CV) of DOX were tested in the potential range from -0.8 to $0.3 \mathrm{~V}$ at $0.05 \mathrm{~V} \mathrm{~s}^{-1}$. The differential pulse voltammograms (DPV) of DOX were recorded in the potential range from -0.8 

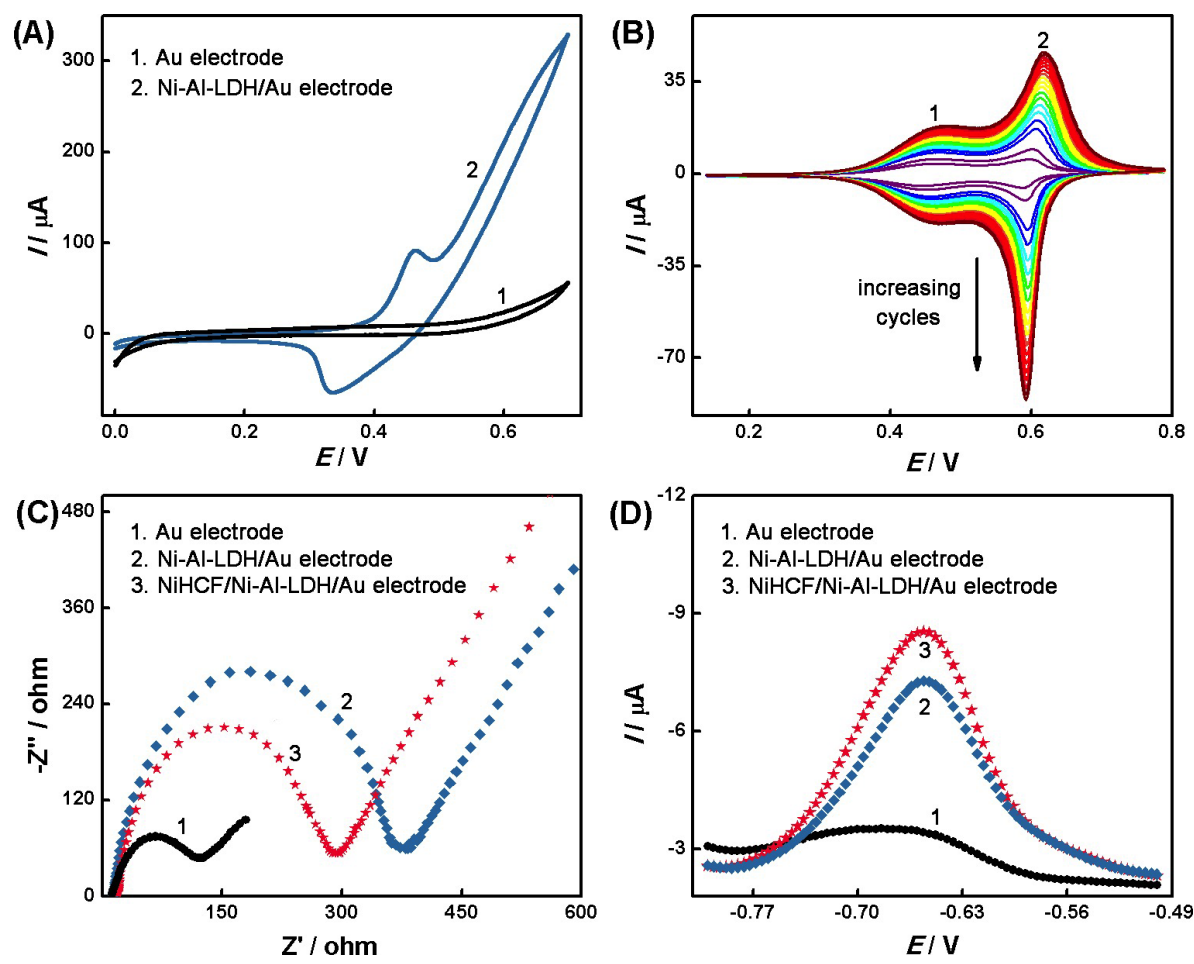

Fig. $2 \mathrm{CV}$ curves of a bare Au electrode and a Ni-Al-LDH/Au electrode in $0.5 \mathrm{~mol} \mathrm{~L}^{-1} \mathrm{KOH}$ at $0.05 \mathrm{~V} \mathrm{~s}^{-1}$ (A), electrodeposition process of NiHCF on Ni-Al-LDH/Au electrode, that is, $\mathrm{CV}$ curves of $\mathrm{Ni}-\mathrm{Al}-\mathrm{LDH} / \mathrm{Au}$ electrode in $1.0 \mathrm{mmol} \mathrm{L}-1 \mathrm{~K}_{3}\left[\mathrm{Fe}(\mathrm{CN})_{6}\right]$ and $1.0 \mathrm{~mol} \mathrm{~L}^{-1} \mathrm{KNO}_{3}$ solution at $0.05 \mathrm{~V} \mathrm{~s}^{-1}$ (B), EIS of a bare Au electrode, a Ni-Al-LDH/Au electrode and a NiHCF/Ni-Al-LDH/Au electrode in $0.1 \mathrm{~mol} \mathrm{~L}^{-1} \mathrm{KCl}$ containing $1 \mathrm{mmol} \mathrm{L}^{-1} \mathrm{~K}_{3}\left[\mathrm{Fe}(\mathrm{CN})_{6}\right] / \mathrm{K}_{4}\left[\mathrm{Fe}(\mathrm{CN})_{6}\right]$ solution $(\mathrm{C})$, the DPV responses of $3.0 \times 10^{-6} \mathrm{~mol} \mathrm{~L}^{-1}$ DOX in PBS buffer solution $(\mathrm{pH} 7.4)$ at the bare Au electrode, Ni-Al-LDH/Au electrode, and NiHCF/Ni-Al-LDH/Au electrode (D).

to $-0.5 \mathrm{~V}$. The modified electrode was immersed into PBS after electrochemical measurement and performed by the potential range from -0.8 to $0.3 \mathrm{~V}$ for 10 cycles at $0.05 \mathrm{~V} \mathrm{~s}^{-1}$.

\section{Results and Discussion}

\section{Characterization of the NiHCF/Ni-Al-LDH/Au sensor}

Morphological characterization. The surface morphologies of the bare $\mathrm{Au}$ and modified electrodes were characterized by SEM technique, as shown in Figs. 1A - 1C. It is clearly noticed that the Ni-Al-LDH layer (Fig. 1B) is uniformly distributed over the surface of the bare Au electrode (Fig. 1A). And the NiHCF nanoparticles $(23-38 \mathrm{~nm})$ were modified on the surface of the Ni-Al-LDH layer to generate a 3D structure (Fig. 1C), thus exhibiting higher electrochemical activity and stronger accumulation abilities, which can be reflected by an increase of the active surface area and the peak current of DOX. In addition, EDX spectroscopy analyses were conducted for the Ni-Al-LDH/ Au electrode (curve 1) and the NiHCF/Ni-Al-LDH/Au electrode (curve 2) to confirm the chemical composition of the obtained nanomaterial (Fig. 1D). Curve 1 exhibits peaks for $\mathrm{N}, \mathrm{O}, \mathrm{Ni}, \mathrm{Al}$ and $\mathrm{Au}$ elements, of which the $\mathrm{N}, \mathrm{O}, \mathrm{Ni}$ and $\mathrm{Al}$ elements should have originated from the $\mathrm{Ni}-\mathrm{Al}-\mathrm{LDH}$, and the $\mathrm{Au}$ element derived from the $\mathrm{Au}$ electrode. Curve 2 exhibits additional peaks for $\mathrm{Fe}$ and $\mathrm{C}$ apart from the above elements. The above results suggest that $\mathrm{NiHCF}$ is effectively electrodeposited on the bare Au electrode surface with Ni-Al-LDH.

Electrochemical characterization. A cyclic voltammetry method was employed to verify the composition of the resulting $\mathrm{NiHCF} /$
Ni-Al-LDH nanocomposite film, and to characterize its electrochemical behaviour. Figure $2 \mathrm{~A}$ depicts the $\mathrm{CVs}$ of a bare $\mathrm{Au}$ electrode and a Ni-Al-LDH/Au electrode in a $0.5 \mathrm{~mol} \mathrm{~L}^{-1}$ $\mathrm{KOH}$ solution. The Ni-Al-LDH/Au electrode exhibits a pair of redox peaks with a potential range from 0.3 to $0.5 \mathrm{~V}$, while the bare Au electrode does not display any electrochemical response. The redox peaks in Fig. 2A (curve 2) are attributed to the reversible redox of $\mathrm{Ni}^{\mathrm{II}} / \mathrm{Ni}^{\mathrm{II}},{ }^{30}$ indicating that $\mathrm{Ni}-\mathrm{Al}-\mathrm{LDHs}$ were successfully electrodeposited on the Au electrode.

Furthermore, in order to demonstrate that NiHCF is electrodeposited on the surface of the $\mathrm{Ni}-\mathrm{Al}-\mathrm{LDH} / \mathrm{Au}$ electrode, the electrodeposition process of NiHCF is shown in Fig. 2B. It is observed that two pairs of redox peaks appear in the range of $0.4-0.6 \mathrm{~V}$, and the peak currents increase significantly with increasing the deposition cycles, indicating the growth of NiHCF layers during CV scanning. In other words, NiHCF has been successfully modified on the surface of the Ni-Al-LDH/Au electrode. Additionally, according to previous reports, ${ }^{30,31}$ two pairs of redox peaks refer to the two different forms of NiHCF, $\mathrm{Ni}_{1.5}\left[\mathrm{Fe}^{\mathrm{III}}(\mathrm{CN})_{6}\right]$ (peak 1) and $\mathrm{K}_{2} \mathrm{Ni}\left[\mathrm{Fe}^{\mathrm{II}}(\mathrm{CN})_{6}\right]$ (peak 2).

Electrochemical impedance spectroscopy (EIS) was recorded to provide detailed information on the impedance property of the modified electrodes. Figure $2 \mathrm{C}$ presents Nyquist diagrams of the bare $\mathrm{Au}$ electrode and modified electrodes in $0.1 \mathrm{~mol} \mathrm{~L}^{-1}$ $\mathrm{KCl}$ containing $1 \mathrm{mmol} \mathrm{L}^{-1} \mathrm{~K}_{3}\left[\mathrm{Fe}(\mathrm{CN})_{6}\right] / \mathrm{K}_{4}\left[\mathrm{Fe}(\mathrm{CN})_{6}\right]$. A small diameter of the semicircle for the bare Au electrode suggests a lower interface electron transfer resistance (curve 1). The modification of $\mathrm{Ni}-\mathrm{Al}-\mathrm{LDH}$ film on the $\mathrm{Au}$ electrode surface results in a significant increase of the impedance, indicating that the weak-conductive Ni-Al-LDH film hinders the electron 

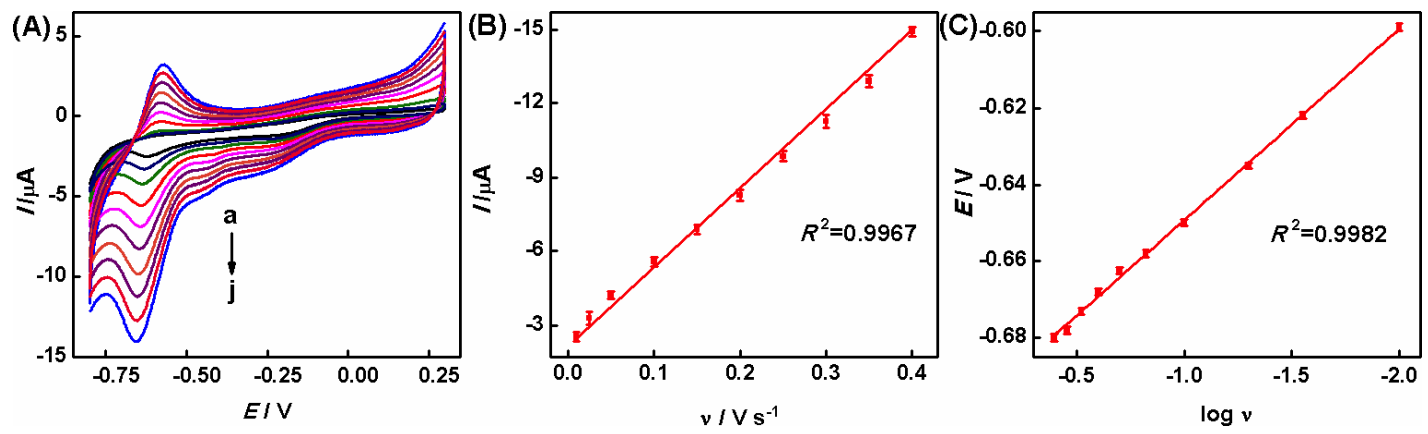

Fig. $3 \mathrm{CV}$ curves of $1.0 \times 10^{-6} \mathrm{~mol} \mathrm{~L}^{-1} \mathrm{DOX}$ on a NiHCF/Ni-Al-LDH/Au electrode with scan rates from 0.01 to $0.4 \mathrm{~V} \mathrm{~s}^{-1}$ (curves a - j, 0.01, 0.025, 0.05, 0.1, 0.15, 0.2, 0.25, 0.30, 0.35, and $0.40 \mathrm{~V} \mathrm{~s}^{-1}$ ) in the PBS (A), the plot of peak current $I v s$. the scan rate $v(\mathrm{~B})$, and the plot of the peak potential $E v s . \log v(\mathrm{C})$.
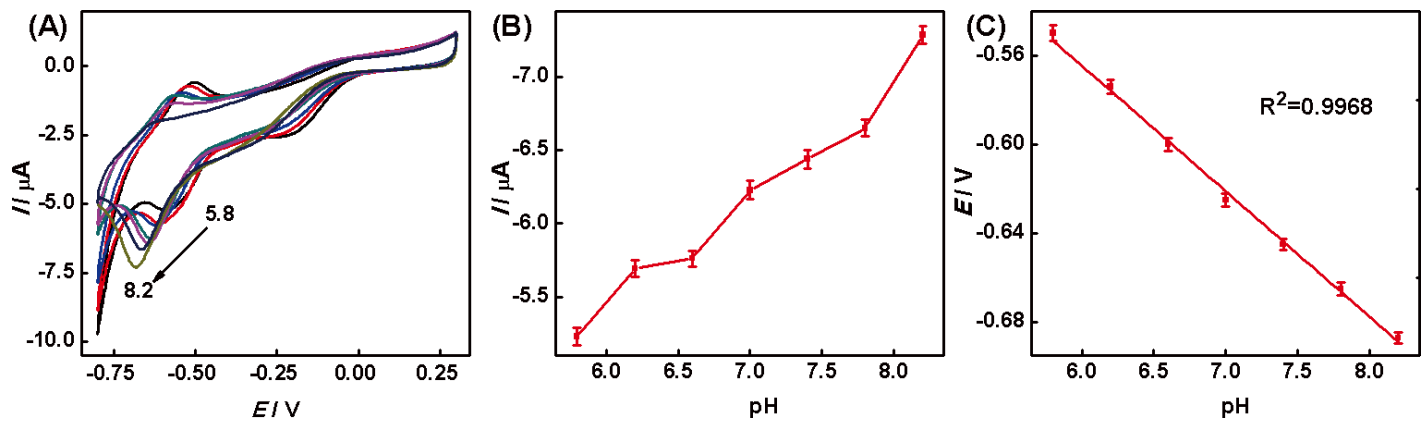

Fig. $4 \mathrm{CV}$ curves of $2.0 \times 10^{-6} \mathrm{~mol} \mathrm{~L}^{-1} \mathrm{DOX}$ at NiHCF/Ni-Al-LDH/Au sensor in PBS with different $\mathrm{pH}$ value ( $\mathrm{pH} 5.8,6.2,6.6,7.0,7.4,7.8$ and 8.2) with the scan rates of $0.05 \mathrm{~V} \mathrm{~s}^{-1}$ (A), plot of peak current $I v s$. pH value (B), and plot of the peak potential $E v s$. pH value (C).

transfer (curve 2). In addition, the semicircle diameter is drastically decreased at the NiHCF/Ni-Al-LDH/Au electrode, which indicates that the participation of NiHCF presents a lower electron transfer resistance and significantly increases the electron transfer rate, and the Ni-Al-LDH provides a large surface area for the deposition of NiHCF. On the whole, the semicircle diameters of the electrodes follows the order of bare $\mathrm{Au}<\mathrm{NiHCF} / \mathrm{Ni}-\mathrm{Al}-\mathrm{LDH} / \mathrm{Au}<\mathrm{Ni}-\mathrm{Al}-\mathrm{LDH} / \mathrm{Au}$. The above result indicates that improved conductivity was obtained by the NiHCF deposited in Ni-Al-LDH film.

Further, the DPV experiment was performed to examine the electrochemical response of each sensor to DOX. Figure 2D displays the DPV response of $3.0 \times 10^{-6} \mathrm{~mol} \mathrm{~L}^{-1}$ DOX at different electrodes. It is obviously noticed that the peak current of the NiHCF/Ni-Al-LDH/Au electrode is greater than that of bare $\mathrm{Au}$ and $\mathrm{Ni}-\mathrm{Al}-\mathrm{LDH} / \mathrm{Au}$ electrodes. This phenomenon proves that the NiHCF/Ni-Al-LDH composite is efficient to promote the accumulation of DOX on the surface of a modified electrode, so as to improve the sensitivity. Besides, according to the Randles-Sevcik theory, the calculated electrochemical active area of the NiHCF/Ni-Al-LDH/Au electrode is $0.5833 \mathrm{~cm}^{2}$, which is much larger than the bare Au electrode $\left(0.0246 \mathrm{~cm}^{2}\right)$ and the Ni-Al-LDH/Au electrode $\left(0.1509 \mathrm{~cm}^{2}\right)$. Thus, the $\mathrm{NiHCF} / \mathrm{Ni}-\mathrm{Al}-\mathrm{LDH} / \mathrm{Au}$ electrode was selected as the optimal sensor in this work.

Electrochemical behavior of DOX on the NiHCF/Ni-Al-LDH/Au electrode

Effect of the scan rate. For the purpose of expounding on the electrochemical mechanism of DOX on the surface of the
$\mathrm{NiHCF} / \mathrm{Ni}-\mathrm{Al}-\mathrm{LDH} / \mathrm{Au}$ sensor, the effect of the scan rate $(v)$ on the response of DOX was investigated by the CV method in a PBS solution containing $1.0 \times 10^{-6} \mathrm{~mol} \mathrm{~L}^{-1} \mathrm{DOX}$, as presented in Fig. 3A. It can be observed that DOX has a pair of quasireversible redox peaks, and the peak currents increase with the scan rates. Because the reduction peak current $\left(I_{\mathrm{pc}}\right)$ is much higher than the corresponding oxidation peak current $\left(I_{\mathrm{pa}}\right)$, the reduction peak was studied in this work. It is pertinent to note that the reduction peak currents of DOX are proportional to the scan rates by following the linear regression equation of $I_{\mathrm{pc}}(\mu \mathrm{A})=-2.451-30.23 v\left(\mathrm{~V} \mathrm{~s}^{-1}\right) \quad\left(R^{2}=0.9967\right)$, as shown in Fig. 3B. The above result suggests an adsorption-controlled electrode process of the DOX at NiHCF/Ni-Al-LDH/Au sensor, thus promoting the accumulation of DOX onto the $\mathrm{NiHCF} / \mathrm{Ni}$ $\mathrm{Al}-\mathrm{LDH} / \mathrm{Au}$ electrode surface for further quantitative analysis.

In addition, it was also observed that the reduction peak potentials $\left(E_{\mathrm{pc}}\right)$ of DOX shifted to the negative direction with an increasing scan rate. The linear relationship of $E_{\mathrm{pc}}$ and the logarithm of the scan rate $(\log v)$ (Fig. 3C) can be expressed as

$$
E_{\mathrm{p}}(\mathrm{V})=-0.6991-0.0498 \log v\left(R^{2}=0.9982\right) .
$$

The slope of the $E_{\mathrm{pc}}-\log v$ plot is equivalent to $2.303 R T / \alpha n F$, of which $\alpha$ refers to the electron transfer coefficient and $n$ corresponds to the transfer electron number. Based on the above linear regression equation, the value of $n$ is equal to 2 for the reduction reaction of DOX, when assuming $\alpha=0.5$ for a quasireversible reaction.

Effect of $\mathrm{pH}$ values. The effect of the $\mathrm{pH}$ on the determination of DOX at the NiHCF/Ni-Al-LDH/Au sensor was studied by 
the CV method. Figure 4A presents the CVs of DOX on the modified electrode in PBS with different $\mathrm{pH}$ values. It is noticed that the reduction peak currents of DOX increase gradually from 5.23 to $7.28 \mu \mathrm{A}$ with the change of the $\mathrm{pH}$ from 5.8 to 8.2 (Fig. 4B). Considering that the $\mathrm{pH}$ value of physiological is 7.4, $\mathrm{pH} 7.4$ is used as the $\mathrm{pH}$ value of the supporting electrolyte to determine DOX.

In addition, the reduction peak potential of DOX goes negative as the $\mathrm{pH}$ value increases. Such a behavior suggests that the proton of DOX participates the electrochemical reaction. The corresponding linear equation $E_{\mathrm{pc}}(\mathrm{V})=-0.2258-0.0565 \mathrm{pH}$ $\left(R^{2}=0.9968\right)$ is obtained through analyzing the relationship of $E_{\mathrm{pc}}$ and $\mathrm{pH}$, as shown in Fig. $4 \mathrm{C}$. According to the Nernst equation, the slope of the linear equation $\left(-0.0565 \mathrm{~V} \mathrm{pH}^{-1}\right)$ is close to the theoretical value of $-0.059 \mathrm{~V} \mathrm{pH}^{-1}$, which suggests that the electrochemical reaction of DOX at the NiHCF/Ni-Al$\mathrm{LDH} / \mathrm{Au}$ electrode should be a two-proton and two-electron process, which is consistent with previous reports. ${ }^{9}$ The reasonable reduction mechanisms of $\mathrm{DOX}$ at the $\mathrm{NiHCF} / \mathrm{Ni}-\mathrm{Al}-$

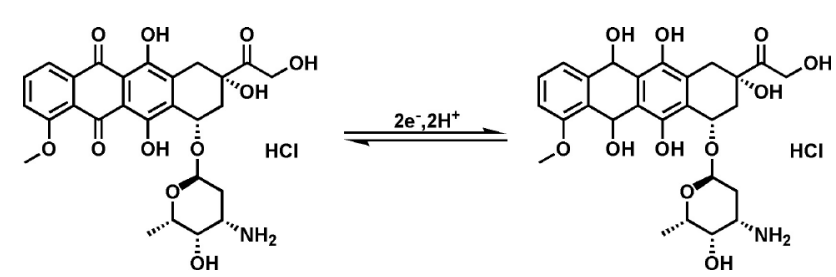

Scheme 2 The reduction mechanism of of DOX at the NiHCF/NiAl-LDH/Au electrode.
LDH/Au electrode can be depicted as in Scheme 2.

Differential pulse voltammetric determination of DOX. The quantificational determination of DOX is conducted by the DPV method under the optimal conditions. Figure 5 depicts the DPV responses of the NiHCF/Ni-Al-LDH/Au sensor toward the different concentrations of DOX. It can be noticed that there is a good linear relationship between the concentration of DOX $(c)$ and the reduction peak current. The corresponding regression

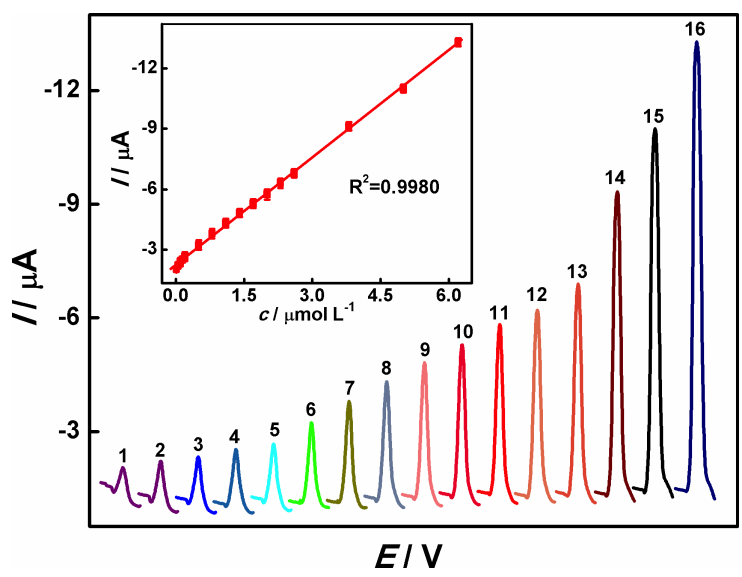

Fig. 5 DPV response of a NiHCF/Ni-Al-LDH/Au electrode with the DOX concentration from $1.0 \times 10^{-8}-6.2 \times 10^{-6} \mathrm{~mol} \mathrm{~L}^{-1}$ (curves $1-16$, $0.01,0.05,0.10,0.15,0.20,0.50,0.80,1.10,1.40,1.70,2.00,2.30$ $2.60,3.80,5.00,6.20 \mathrm{~mol} \mathrm{~L}^{-1}$ ) in PBS (pH 7.4); the inset shows a plot of current $I v s$. the concentrations of DOX.

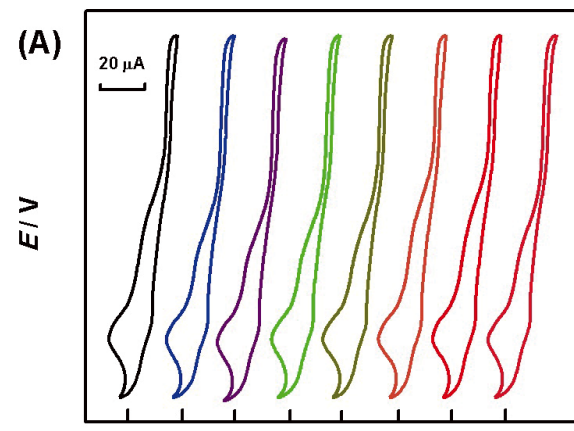

$\mathrm{DOX}+\mathrm{VB} 6+\mathrm{VC}+\mathrm{LYS}+\mathrm{SER}+\mathrm{GLY}+\mathrm{GLU}+\mathrm{SC}$

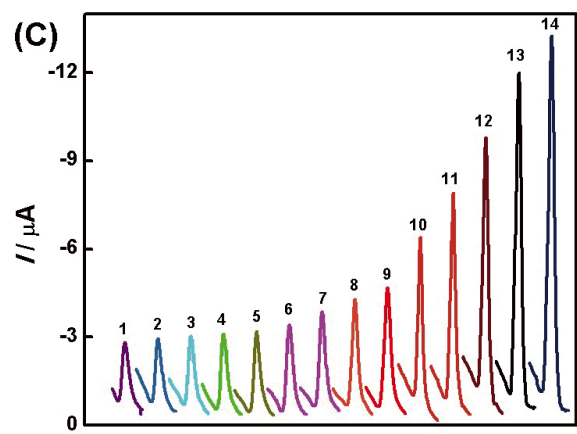

$E / V$
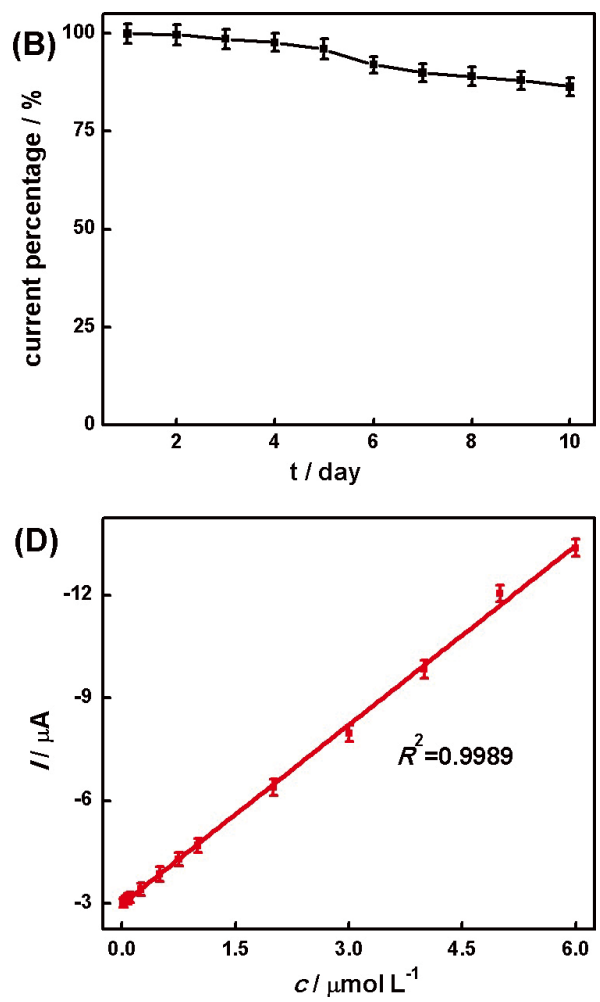

Fig. 6 Effect of potential interferents on the detection of DOX for a NiHCF/Ni-Al-LDH/Au electrode (A), current responses of a NiHCF/Ni-Al-LDH/Au electrode toward $1.0 \times 10^{-6} \mathrm{~mol} \mathrm{~L}^{-1} \mathrm{DOX}$ day-today (B), DPV responses of a NiHCF/Ni-Al-LDH/Au electrode with the DOX concentration from $1.0 \times 10^{-8}-6.0 \times 10^{-6} \mathrm{~mol} \mathrm{~L}^{-1}$ (curves $1-14,0.01,0.025,0.05,0.075,0.10,0.25,0.50,0.75,1.00,2.00$, $3.00,4.00,5.00$ and $\left.6.00 \mu \mathrm{mol} \mathrm{L}^{-1}\right)$ in the real sample (C), plot of current $I v s$. concentrations of DOX (D). 
Table 1 Recovery studies of DOX in blood serum samples

\begin{tabular}{cccc}
\hline Added $/ \mu \mathrm{mol} \mathrm{L}$ & -1 & Found $/ \mu \mathrm{mol} \mathrm{L}$ & \\
\hline 1.00 & 0.96 & 96.02 & 4.21 \\
2.00 & 2.01 & 100.51 & 2.51 \\
3.00 & 2.98 & 99.33 & 2.35 \\
4.00 & 4.06 & 101.50 & 2.73 \\
\hline
\end{tabular}

equation is $I(\mu \mathrm{A})=-2.2543-1.8479 c\left(R^{2}=0.9980\right)$, with a linear range of $1.0 \times 10^{-8}-6.2 \times 10^{-6} \mathrm{~mol} \mathrm{~L}^{-1}$, a LOD of $1.9 \times 10^{-9} \mathrm{~mol} \mathrm{~L}^{-1}(S / N=3)$ and a sensibility of $14.71 \mathrm{~A} \mathrm{~mol} \mathrm{~L}^{-1} \mathrm{~cm}^{-2}$. Additionally, compared to the reported DOX sensors in the aspect of detection performance,,$^{8-11,32}$ the present sensor exhibits a wider linear range and a lower LOD, as listed in Table S1 (Supporting Information).

Practical application of the NiHCF/Ni-Al-LDH/Au sensor. The selectivity of the proposed DOX sensor is one of the most important indicators for an analytical method, especially in the presence of coexisting species in a real sample. Hence, an interference test was examined based on the $\mathrm{CV}$ response of the $\mathrm{NiHCF} / \mathrm{Ni}-\mathrm{Al}-\mathrm{LDH} / \mathrm{Au}$ sensor in $3.0 \times 10^{-6} \mathrm{~mol} \mathrm{~L}^{-1} \mathrm{DOX}$ and presence of $3.0 \times 10^{-4} \mathrm{~mol} \mathrm{~L}^{-1}$ possible interferents, as shown in Fig. 6A.

It is noticed that the prepared $\mathrm{NiHCF} / \mathrm{Ni}-\mathrm{Al}-\mathrm{LDH} / \mathrm{Au}$ sensor delivers a good response to $3.0 \times 10^{-6} \mathrm{~mol} \mathrm{~L}^{-1} \mathrm{DOX}$, and the addition of 100-fold concentrations of vitamin B6 (VB6), vitamin C (VC), L-lysine (LYS), L-serine (SER), glycine (GLY), glucose (GLU) and sodium citrate (SC) have no influence on the response of the DOX, suggesting that the coexisting species mentioned above have almost no interference on the determination of DOX. That is to say, the proposed NiHCF/ $\mathrm{Ni}-\mathrm{Al}-\mathrm{LDH} / \mathrm{Au}$ sensor has an excellent anti-interference for DOX.

The reproducibility of the NiHCF/Ni-Al-LDH/Au sensor is evaluated by detecting the reduction peak current of $1.0 \times 10^{-6}$ mol L-1 DOX for five parallel measurements using the CV method. The obtained relative standard deviation (RSD) is $4.2 \%$, indicating that the $\mathrm{NiHCF} / \mathrm{Ni}-\mathrm{Al}-\mathrm{LDH} / \mathrm{Au}$ possesses good reproducibility. Additionally, the stability of the NiHCF/ Ni-Al-LDH/Au sensor is determined by monitoring of its DPV responses towards $1.0 \times 10^{-6} \mathrm{~mol} \mathrm{~L}^{-1} \mathrm{DOX}$ during 10 days (cf. Fig. 6B). Apparently, the current response of the NiHCF/Ni-Al$\mathrm{LDH} / \mathrm{Au}$ sensor still retains about $86.4 \%$ of its initial value after 10 days, revealing good stability of $\mathrm{NiHCF} / \mathrm{Ni}-\mathrm{Al}-\mathrm{LDH} / \mathrm{Au}$ sensor. In order to evaluate its performance in real samples, the analytical response of DOX in human blood serum was analyzed using a standard addition method, as depicted in Figs. 6C and $6 \mathrm{D}$. The corresponding regression equation is $I(\mu \mathrm{A})=-2.9919$ $-1.7420 c\left(R^{2}=0.9989\right.$, of which $c$ refers to the concentration of DOX), and the linear range and sensibility for the real sample on $\mathrm{NiHCF} / \mathrm{Ni}-\mathrm{Al}-\mathrm{LDH} / \mathrm{Au}$ sensor were calculated to be $1.0 \times 10^{-8}$ $-6.0 \times 10^{-6} \mathrm{~mol} \mathrm{~L}^{-1}$ and $13.86 \mathrm{~A} \mathrm{~mol} \mathrm{~L}^{-1} \mathrm{~cm}^{-2}$, respectively. The LOD was evaluated to be $2.5 \times 10^{-9} \mathrm{~mol} \mathrm{~L}^{-1}(S / N=3)$, respectively.

Additionally, the recovery of DOX varied from 96.02 to $101.50 \%$ (cf. Table 1) with a RSD between 2.35 and $4.21 \%$, suggesting good accuracy of this method. The results illuminate that the proposed $\mathrm{NiHCF} / \mathrm{Ni}-\mathrm{Al}-\mathrm{LDH} / \mathrm{Au}$ sensor is satisfactory for detecting DOX in human blood serum.

\section{Conclusions}

In this study, the sensitive electrochemical sensor for detecting DOX based on the NiHCFNi-Al-LDH modified Au electrode was fabricated using an electrochemical deposition method. The modified electrode exhibits excellent electrocatalytic activity towards the DOX. Under the studied conditions, DOX is determined at the NiHCF/Ni-Al-LDH/Au sensor using DPV in standard samples and in human blood serum with a wide linear range and low detection limit. The fabricated $\mathrm{NiHCF} /$ $\mathrm{Ni}-\mathrm{Al}-\mathrm{LDH} / \mathrm{Au}$ sensor is sensitive with good stability, low cost and large surface area, and presents good selectivity for the direct detection of DOX. As a convenient operation sensor, it seems to be of great practical value for some real applications, such as pharmacokinetic studies in cancer patients.

\section{Acknowledgements}

This work was supported by the Doctor Fund of Shanxi Normal University (0505/02070468).

\section{Supporting Information}

Table $\mathrm{S} 1$ is listed in the material. This material is available free of charge on the Web at http://www.jsac.or.jp/analsci/.

\section{References}

1. J. A. Ho, N. Fan, A. F. Jou, L. Wu, and T. Sun, Talanta, 2012, 99, 683.

2. Q. Q. Li, J. D. Xu, W. J. Wang, X. X. Cao, Q. Chen, and F. Tang, Clin. Cancer Res., 2009, 15, 2657.

3. Z. F. Xu, P. H. Deng, J. H. Li, L. Xu, and S. P. Tang, Mater. Sci. Eng., B, 2017, 218, 31 .

4. E. Manasa, K. V. Prakash, P. R. Pratap, and S. Susena, Int. J. Pharm., Chem. Biol. Sci, 2013, 3, 1006.

5. I. Sardi, G. L. Marca, M. G. Giovannini, S. Malvagia, R. Guerrini, L. Genitori, M. Massimino, and M. Aricò, Cancer Chemother. Pharmacol., 2011, 67, 1333.

6. S. R. Dharmalingam, S. Ramamurthy, K. Chidambaram, and S. Nadaraju, Trop. J. Pharm. Res., 2014, 13, 409.

7. W. Z. Ma, J. L. Wang, Q. Guo, and P. F. Tu, J. Pharm. Biomed. Anal., 2015, 111, 215.

8. J. Soleymani, M. Hasanzadeh, N. Shadjou, M. K. Jafari, J. V. Gharamaleki, M. Yadollahi, and A. Jouyban, Mater. Sci. Eng., C, 2016, 61, 638.

9. J. Soleymani, M. Hasanzadeh, M. Eskandani, M. Khoubnasabjafari, N. Shadjou, and A. Jouyban, Mater. Sci. Eng., C, 2017, 77, 790 .

10. E. Haghshenas, T. Madrakian, and A. Afkhami, Anal. Bioanal. Chem., 2016, 408, 2577.

11. Y. Zhang, J. Zheng, J. Wang, and M. D. Guo, Chem. J. Chin. Univ., 2016, 37, 860.

12. P. M. Alizadeh, M. Hasanzadeh, J. Soleymani, J. V. Gharamaleki, and A. Jouyban. Microchem. J., 2019, 145, 450.

13. Y. X. Li, L. Huang, X. P. Wang, and Y. T. Chen, Anal. Sci., 2017, 33, 1105.

14. D. N. Mazaafrianto, A. Ishida, M. Maeki, H. Tani, and M. Tokeshi, Anal. Sci., 2019, 35, 1221.

15. L. Mardani, M. T. Vardini, M. Es'haghi, and E. G. Kalhor, Anal. Sci., 2019, 35, 1173. 
16. Q. Wang and D. O'Hare, Chem. Rev., 2012, 112, 4124.

17. G. L. Fan, F. Li, D. G. Evans, and X. Duan, Chem. Soc. Rev., 2014, 43, 7040.

18. Z. Gu, J. J. Athertonab, and Z. P. Xu, Chem. Commun., 2015, 51, 3024.

19. L. P. Wu, J. Li, and H. M. Zhang, Electroanalysis, 2015, 27, 1195.

20. B. Rezaei, H. Khosropour, A. A. Ensafi, M. Dinari, and A. Nabiyan, RSC Adv., 2015, 5, 75756.

21. T. R. Zhan, Y. Song, X. J. Li, and W. G. Hou, Mater. Sci. Eng., C, 2016, 64, 354.

22. G. Layrac, D. Tichit, J. Larionova, Y. Guari, and C. Guerin, J. Phys. Chem. C, 2011, 115, 3263.

23. K. A. Zeynali and R. Amini, Electroanalysis, 2017, 29, 635.

24. C. D. Wessells, M. T. McDowell, S. V. Peddada, M. Pasta,
R. A. Huggins, and Y Cui, ACS Nano, 2012, 6, 1688.

25. C. D. Wessells, S. V. Peddada, R. A. Huggins, and Y. Cui, Nano Lett., 2011, 11, 5421.

26. Z. D. Wang, X. G. Hao, Z. L. Zhang, S. B. Liu, Z. H. Liang, and G. Q. Guan, Sens. Actuators, B, 2012, 162, 353.

27. M. H. Mashhadizadeh, T. Yousefi, and A. N. Golikand, Electrochim. Acta, 2012, 59, 321.

28. P. C. Pandey and A. K. Pandey, Analyst, 2013, 138, 952.

29. Y. L. Wang, Y. P. Rui, F. J. Li, and M. G. Li, Electrochim. Acta, 2014, 117, 398.

30. Y. L. Wang, H. Q. Ji, W. Peng, L. Liu, F. Gao, and M. G. Li, Int. J. Hydrogen Energ., 2012, 37, 9324.

31. L. Wang, D. Wang, X. Dong, Z. Zhang, X. Pei, X. Chen, B. Chen, and J. Jin, Chem. Commun., 2011, 47, 3556.

32. Y. Hahn and Y. Lee, Arch. Pharm. Res., 2004, 27, 31. 